\title{
Math anxiety: A review of its cognitive consequences, psychophysiological correlates, and brain bases
}

\author{
Macarena Suárez-Pellicioni ${ }^{1}$ - María Isabel Núñez-Peña ${ }^{1,2} \cdot$ Àngels Colomé $^{1}$
}

Published online: 7 August 2015

(C) Psychonomic Society, Inc. 2015

\begin{abstract}
A decade has passed since the last published review of math anxiety, which was carried out by Ashcraft and Ridley (2005). Given the considerable interest aroused by this topic in recent years and the growing number of publications related to it, the present article aims to provide a full and updated review of the field, ranging from the initial studies of the impact of math anxiety on numerical cognition, to the latest research exploring its electrophysiological correlates and brain bases from a cognitive neuroscience perspective. Finally, this review describes the factors and mechanisms that have been claimed to play a role in the origins and/or maintenance of math anxiety, and it examines in detail the main explanations proposed to account for the negative effects of math anxiety on performance: competition for working memory resources, a deficit in a low-level numerical representation, and inhibition/attentional control deficit.
\end{abstract}

Keywords Math anxiety $\cdot$ Numerical cognition $\cdot$ Brain correlates $\cdot$ fMRI $\cdot$ ERPs $\cdot$ Working memory $\cdot$ Inhibitory deficit · Attentional control deficit · Numerical magnitude representation

As far as we know, the tutorial review carried out by Ashcraft and Ridley (2005) and published in Campbell's Handbook of

María Isabel Núñez-Peña

inunez@ub.edu

$1 \quad$ Faculty of Psychology and Institute for Brain, Cognition and Behavior (IR3C), University of Barcelona, Barcelona, Spain

2 Department of Behavioral Sciences Methodology, Faculty of Psychology, University of Barcelona, Passeig Vall d'Hebron, 171, 08035 Barcelona, Spain
Mathematical Cognition is the only general review carried out in the field of math anxiety to date. Given that several studies have been conducted since then, this review article aims to examine the current state of knowledge about math anxiety, ranging from the initial studies of the effect of math anxiety on numerical cognition (conducted by Ashcraft and collaborators), through to the most recent publications on the bases of math anxiety from the perspective of cognitive neuroscience. This review also updates the main explanations for the effects of math anxiety on math performance, including a recent account on which our discussion of the latest findings on this topic is based and that has not previously been examined in a review.

With this objective in mind, we begin by defining math anxiety and examining its relationship with other variables. We then explore the principal proposed explanations for its negative effects on performance (competition for working memory [WM] resources, inhibitory/attentional control deficit, and deficit in low-level numerical processing), as well as the main theories regarding its origin and maintenance (exposure to negative experiences, genetic factors, the role of math ability, attention, WM, and error processing). We end the review by examining the brain correlates of math anxiety - specifically, the findings of research using event-related potentials (ERPs) and functional magnetic resonance imaging (fMRI) and also by making certain recommendations that teachers, parents, and psychologists might take into account in order to help children reduce their levels of mathematical anxiety.

\section{What is math anxiety?}

Several definitions of math anxiety (hereinafter, MA) have been proposed over the years, including "an irrational and impeditive dread of mathematics" (Lazarus, 1974, p. 16), 
"the panic, helplessness, paralysis and mental disorganization that arises among some people when they are required to solve a mathematical problem" (Tobias, 1978, p. 65), a "general fear of contact with mathematics" (Hembree, 1990, p. 45), or the "feeling of tension, apprehension or even dread, that interferes with the ordinary manipulation of numbers and the solving of mathematical problems" (Ashcraft \& Faust, 1994, p. 98). Common to all these definitions is the idea that for some people dealing with numbers or math-related situations evokes an emotional response that disrupts their performance.

In an attempt to explain why some of her students failed mathematics courses despite proficiency in other subjects, Gough coined the term mathemaphobia to refer to this type of anxiety (Gough, 1954). Shortly afterward, Dreger and Aiken (1957) noted that although emotional factors may disrupt mastery of mathematics, there was an important lack of research attempting to investigate the emotional problems associated with arithmetic and mathematic problem solving (Dreger \& Aiken, 1957). In seeking to address this situation, they became the first to introduce standardized assessment into the study of what they called number anxiety, specifically by adding three questions about emotional reactions toward math to the Taylor Manifest Anxiety Scale (e.g., "Many times when I see a math problem I just freeze up"; Taylor, 1953) and renaming it the Numerical Anxiety Scale.

Despite this initial attempt to address math anxiety, the first formal instrument for measuring the construct did not appear until 15 years later, when Richardson and Suinn (1972) published their Mathematics Anxiety Rating Scale (MARS). The MARS is a 98 -item rating scale on which respondents indicate, using a 5-point Likert scale, how anxious they would feel in situations ranging from formal math settings to informal everyday situations. Publication of the MARS led to the development of other, shorter and similar scales in English, such as the 25-item abbreviated version of the MARS (sMARS; Alexander \& Martray, 1989), the 12-item Fennema-Sherman Mathematics Anxiety Scale (MAS; Fennema \& Sherman, 1976), the six-item Sandman Anxiety Towards Mathematics Scale (ATMS; Sandman, 1980), the 24-item Math Anxiety Rating Scale Revised (MARS-R; Plake \& Parker, 1982), or the 9-item Abbreviated Math Anxiety Scale (AMAS; Hopko, Mahadevan, Bare, \& Hunt, 2003). Adaptations of some of these instruments have also been validated in other languages [e.g., the Spanish version of the Shortened Math Anxiety Rating Scale (Núñez-Peña, Suárez-Pellicioni, Guilera, \& Mercadé-Carranza, 2013) or the Single-Item Math Anxiety Scale (Núñez-Peña, Guilera, \& Suárez-Pellicioni, 2013; SIMA)].

Besides proposing the Numerical Anxiety Scale, Dreger and Aiken (1957) also hypothesized that MA was conceptually distinct from general anxiety. Some years later, a metaanalysis by Hembree (1990) corroborated this prediction by reporting a correlation of .38 between MA and trait anxiety, showing that although individuals who are high in MA also tend to score high on trait anxiety, these two types of anxieties are clearly separated. Moreover, MA has also been associated with test anxiety. In this respect, Dew, Galassi, and Galassi (1983) used different instruments for measuring MA (MAS, ATMS, and the original MARS) and a measure of test anxiety (the Spielberger Test Anxiety Inventory; Spielberger, 1977) to study the relationship between these two types of anxiety. They found that fully two thirds of the variance in MA was shared among the different MA assessments (MAS, ATMS, MARS) and that it was not explained by test anxiety. In a similar vein, the study by Hunsley (1978), exploring similarities and differences in the cognitive processes involved in math and test anxiety, suggested that, in the context of mathematical examinations, MA had incremental validity in the prediction of many cognitive processes (e.g., subjective ratings of exam importance, postexam performance estimations, and ratings of performance satisfaction) that were related to MA but not to test anxiety. Finally, the previously mentioned meta-analysis (Hembree, 1990) showed a correlation of .52 between MA and test anxiety, which, after correction for attenuation, gave a coefficient of determination of .37, indicating that only $37 \%$ of one construct's variance was predictable from the variance of the other. On the basis of these findings, researchers claimed that "the two constructs do not seem to be interchangeable" (Dew et al., 1983, p. 446) or that "it seems unlikely that mathematics anxiety is purely restricted to testing" (Hembree, 1990, p. 45), with MA deserving to be considered a separate construct.

Although MA is not recognized in the Diagnostic and Statistical Manual of Mental Disorders (DSM-IV; American Psychiatric Association, 2000), it has been suggested that, in contrast to other subjects taught through formal education, math appears to generate enough difficulty to be considered the object of a genuine phobia (Ashcraft \& Ridley, 2005). Similarly, some researchers had previously claimed that MA fits the classical definition of a genuine phobia: It is a state anxiety reaction, it shows elevated cognitive and physiological arousal, and it is a stimulus- and situation-specific learned fear (Faust, 1992). In this regard, Faust found physiological evidence of increasing reactivity (i.e., changes in heart rate) when math-anxious individuals performed math tasks of growing difficulty, but not for a verbal task of similar difficulty, with no kind of reactivity being observed for the low math-anxious (LMA) group.

These physiological responses of high math-anxious (HMA) individuals might underlie their negative attitudes toward this discipline. In this respect, Hembree (1990) found a negative correlation between MA and enjoyment of math (grades 5-12, -.75; college, -.47), self confidence in math (grades 6-11,-.82; college, -.65), self-concept in math $(-.71)$, motivation in math (-.64), opinion about the usefulness of math (-.37), and attitudes toward math teachers (-.46). 
Thus, the sum of MA and negative attitudes toward math might result in the avoidance of math-related situations and numeric contents. In short, if one dislikes math and feels that one is terrible at this subject, one will probably avoid math as much as possible and not enroll in math beyond basic graduation requirements (Ashcraft, Krause, \& Hopko, 2007). Related to these findings is the study by LeFevre, Kulak, and Heymans (1992), who constructed a regression model to predict students' choices of university majors varying in mathematical content. They found that whereas age, fluency in math, and experience with math contributed significantly to the prediction, a "math affect" factor, composed of MA and avoidance measures, more than doubled the variance accounted for by the model. In this regard, the meta-analysis by Hembree (1990) showed that MA significantly correlated with the extent of enrollment in high school math $(r=-.31)$, with the intent to enroll in college math $(r=-.32)$, and with the number of high school math courses taken $(r=-.45)$.

The unavoidable consequence of MA, math avoidance, and negative attitudes toward this subject is that HMA individuals tend to show worse performance when their math achievement is measured with standardized tests (Ashcraft \& Krause, 2007). Negative correlations have been reported between MA and math achievement for both precollege (-.30 in Hembree, $1990 ;-.27$ in Ma, 1999) and college (-.27 in Hembree, 1990) levels. However, the picture is less clear with regard to children: Whereas the negative correlation between MA and math achievement is evident for older elementary-school-aged children (i.e., from 10 to 14 years old; Chiu \& Henry, 1990), the relationship between these two variables in younger children is a matter of debate. More specifically, whereas some studies have found no evidence of a relationship between MA and calculation ability in 6- to 9-year-old children (Krinzinger, Kaufmann, \& Willmes, 2009; Thomas \& Dowker, 2000), others have reported that second and third graders ( $7-9$ years old) showed a negative significant correlation between their scores on MA and their performance on a mathematical reasoning and numerical operation task (Wu, Barth, Amin, Malcarne, \& Menon, 2012), as well as in a task presenting increasingly difficult math-related word problems (although only for children with high WM capacity - see "A high level of WM capacity" section below; Ramirez, Gunderson, Levine, \& Beilock, 2013).

It should also be noted that the most recent Program for International Student Assessment (Organisation for Economic Co-operation and Development [OECD], 2013) report showed that the prevalence of MA was higher than previously thought: $61 \%$ of 15 -year-old students from OECD countries expressed concern at the prospect of getting bad grades in math, around $30 \%$ reported feeling incapable or nervous when solving a math problem, $33 \%$ acknowledged feeling tense when solving math homework, and $59 \%$ reported being worried about the difficulty of math classes. Furthermore, MA was shown to have a worrying negative effect on performance: Greater MA was associated with a decline in performance of 34 points, the equivalent of almost one year of school. These data are cause for concern, given that math is one of the foundations of our highly technological society, a society that offers more and better employment opportunities to those who are well trained in math and who can help in the development of key areas such as science, technology, or engineering. This means that MA impacts negatively on the professional development, employment opportunities, and even salary prospects of those students and future workers who suffer from it.

However, the effects of MA are not only restricted to academic contexts, but have consequences for other aspects of life. For example, it has been shown that MA prevents consumers from computing prices accurately, leading them to prefer easier-to-process dollars-off price promotions (absolute discounts; e.g., $\$ 10$ off, regular price $\$ 50$ ) to percentage-off formats (relative discounts; e.g., $20 \%$ off, regular price \$50), even when the latter implied a higher discount than the former (Suri, Monroe, \& Koe, 2013). In addition, a significant negative relationship has been found between levels of MA and selfefficacy in performing numerical and drug calculations in nursing students (McMullan, Jones, \& Lea, 2012).

\section{Math anxiety and numerical cognition}

Until the 1990s, research on MA was mainly based on assessing the relationship between MA and math attitudes, math achievement, and other types of anxiety. A number of studies also assessed the effect that the characteristics of arithmetical problems had on performance, revealing some of the most fundamental effects in this field, such as the problem size effect (i.e., reaction times [RTs] and errors increase as the size of the problem increases; Ashcraft \& Battaglia, 1978) or the split effect (i.e., RTs and errors decrease as the proposed solution in an arithmetic verification task deviates more from the correct one; Ashcraft \& Battaglia, 1978).

However, it was not until the study by Ashcraft and Faust (1994) that the research on MA and numerical cognition converged. Until that point, there was no evidence to support a relationship between MA and differential processing of math problems. To assess the existence of this relationship, Ashcraft and Faust formed four groups according to the participants' levels of MA and manipulated the complexity of the task by presenting four stimulus sets in a verification task: two simple sets including single-digit additions and multiplications, and two complex sets including two-digit additions and mixed arithmetic operations. Their findings can be summarized in 
three main points. First, they found that the four anxiety groups performed rather similarly in the simple addition and multiplication tasks, suggesting that the effect of MA on RTs was either very weak or nonexistent in the overlearned simple arithmetic operations of addition and multiplication. By contrast, complex additions and mixed arithmetic operations were challenging enough to elicit the effects of MA. Given this finding, the authors proposed the anxiety-complexity effect, defined as a deterioration in HMA individuals' performance when the stimulus conditions become more difficult or complex (Faust, Ashcraft, \& Fleck, 1996). Second, they found that Group 4 (highest HMA) was frequently faster than Group 3 (middle HMA), and sometimes faster than Group 2 (middle LMA), but showed the highest error rates, suggesting that this group seemed to sacrifice accuracy for speed (i.e., speed-accuracy trade-off). Finally, for complex additions, the HMA groups took the same time to reject false carry problems, regardless of where the incorrect value was located (units or tens column), suggesting that they did not take advantage of the opportunity to self-terminate processing upon detecting the incorrect value in the units column, a shortcut that their LMA peers seemed to employ. The authors explained the latter two findings as being manifestations of two different types of avoidance. The first implies a global avoidance effect (i.e., enrolling in fewer math courses or selecting college majors involving less math content), which would have left HMA individuals less well-trained in mathematics; being less knowledgeable about mathematics, they would have been less keen to explore special strategies, thus failing in selfterminating processing when the incorrect value was presented in the units column. In addition, however, Ashcraft and Faust claimed the existence of a local avoidance effect resulting from the desire to complete the math task as soon as possible, so as to leave the uncomfortable situation of math problem solving. The latter type of avoidance would be responsible for the speed-accuracy trade-off, given that HMA individuals would have responded faster simply to finish the math task as soon as possible.

Given that Ashcraft and Faust (1994) found that HMA individuals seemed not to use the self-terminating strategy when verifying false problems, Faust et al. (1996) sought to investigate this aspect further by studying the split effect, another well-known effect in mathematical cognition, which has been related to the use of different strategies. Large-split solutions in an arithmetic verification task (when the proposed solution is far away from the correct one; e.g., $3+7=25$ ) are considered to be solved by using a plausibility strategy - that is, by easily ruling out the clearly incorrect solution without completing the regular calculation process. Conversely, smallsplit solutions (i.e., when the proposed solution is very close to the correct one; e.g., $3+7=11$ ) are considered to be solved by means of an exhaustive verification strategy, given that the exact calculation is necessary to give a response. In addition to the classical measures of RTs and error rates, Faust et al. (1996) created a new one, called flawed scores, which was computed as the combination of two scores: the proportion of errors and the proportion of extreme RTs. Since they were considered to reflect both those difficulties that yielded an error and those that generated an inordinately slow RT (Faust et al., 1996), flawed scores were taken to show participants' difficulties in processing. The results obtained by Faust et al. can be summarized as follows: First, they found that the greatest effects of MA were observed for complex problems but not for simple ones, thus supporting the anxietycomplexity effect described by Ashcraft and Faust (1994). Second, very interesting results emerged for the split effect: here, they found that whereas LMA individuals showed the expected result on flawed scores (i.e., higher for small-split solutions and reduced for the easiest large-split ones), the highest HMA group (Group 4) showed an unexpected pattern, generating more flawed scores as the level of split increased. In other words, the highest-MA group showed a higher proportion of flawed scores as the proposed solution deviated more from the correct one, leading to a difference between math-anxious groups in the largest-split solution, the one that should be the easiest to rule out due to its being clearly implausible. The authors interpreted this finding as probably showing an overall difference in some decision or evaluation stage of performance on the part of highly anxious participants (Faust et al., 1996).

Despite the surprising nature of this finding, the relationship between MA and the split effect was not investigated in greater depth until the recent study by Suárez-Pellicioni, Núñez-Peña, and Colomé (2013a). These researchers aimed to replicate Ashcraft and colleagues' findings on flawed scores while also recording electrophysiological evidence in an attempt to account for such a curious result. To this end, they formed two groups of participants who were extreme on their MA scores (measured with the sMARS test; NúñezPeña, Suárez-Pellicioni, et al., 2013) and then administered a single-digit addition verification task (addends between 2 and 9). The solutions could be correct (e.g., $4+7=11$ ), small-split ( \pm 1 from the correct solution; e.g., $4+7=12$ ), or large-split (+ 14 from the correct solution; e.g., $4+7=25$ ). Apart from reproducing the previous findings on flawed scores (i.e., a higher percentage of flawed scores for large-split solutions only for the HMA group), Suárez-Pellicioni et al. (2013a) also found a P600/P3b component of greater amplitude and delayed latency for the HMA group as compared with their LMA counterparts, but once again, only for large-split solutions. Given that the amplitude of this component is taken to indicate the amount of attentional resources allocated to a stimulus, and its latency is considered to reflect the speed of stimulus processing, these results were interpreted as showing that HMA individuals were spending more time and resources 
on processing a solution that could easily have been ruled out due to being obviously incorrect. The authors concluded that this pattern of flawed scores suggested that these individuals had succumbed to the distracting nature of large-split solutions, which differed greatly from the correct solution and from the addends.

\section{Explanations of math anxiety}

\section{MA as task-related competition for WM resources}

The pioneering researchers in the field of MA interpreted its effects within the framework of processing efficiency theory (PET; Eysenck \& Calvo, 1992), one of the most important theories aiming to explain the relationship between anxiety and performance in cognitive tasks. According to PET, the anxiety reaction involves worrying intrusive thoughts that consume the limited attentional resources of the central executive of WM, which are therefore less available for current task processing. This implies that the adverse effects of anxiety on performance should be greater on tasks imposing substantial demands on the processing capacity of the central executive of WM. Ashcraft and collaborators extended this explanation to the field of MA by claiming that MA would affect performance only if the task depended on substantial WM processing - that is, only for complex arithmetic (i.e., the anxiety-complexity effect) - and because WM resources would be devoted to the anxious reaction (i.e., worrying intrusive thoughts) generated by the math task rather than to task processing (Ashcraft \& Faust, 1994; Faust et al., 1996).

However, this hypothesized relationship between MA and WM was not formally investigated until the study by Ashcraft and Kirk (2001). In their first experiment, they assessed participants' WM capacity by requiring them to store an increasing number of words or digits in WM while processing simple verbal or arithmetic tasks. In the verbal task, participants heard a number of simple sentences (e.g., "Last fall the farmers had a good harvest"), had to answer a simple question (e.g., "When?"), and then had to recall the final word of each of the sentences (e.g., "harvest") in serial order. In the numeric task, participants had to solve an arithmetic verification task (e.g., $5+2=$ ?; $6+3=$ ?) and then recall the last addends of each operation, in order (e.g., 2, 3). The authors carried out a correlational analysis and found that higher MA was associated with lower WM span, but only for the arithmetic verification task, with almost no relationship being observed between MA and language-based span. In a second experiment, participants were tested in a dual-task paradigm in which they were asked to hold a string of either two or six random letters in WM while solving an addition problem (involving carrying and noncarrying additions), and to recall the letters presented in the first place. The results showed that errors increased substantially when memory load was heavy (i.e., six letters), especially for the addition problems requiring carrying. This pattern was apparent in all of the groups, but was especially dramatic in the highest math-anxious one. By contrast, when the WM load was light (i.e., two letters) and no carrying was involved, error rates were quite low and very similar across the MA groups. As a whole, the authors concluded that higher levels of MA were related to lower available WM capacity, but not as a stable characteristic; rather, it was postulated that HMA individuals experienced a temporary reduction in processing capacity when their anxiety was aroused, which would hamper their performance in any math task that relied substantially on WM. In short, according to Ashcraft and Kirk's account, MA functions like a dual-task procedure, leading to diminished performance in any primary math task relying on resources from WM.

\section{MA as a deficit in low-level numerical representation}

For several years, the explanation put forward by Ashcraft and colleagues as to why MA affects math performance remained the prominent one. Consequently, differences between mathanxious groups were only expected for complex arithmeticthat is, the kind of operations requiring more resources from WM (e.g., carrying, borrowing, etc.).

Within this context, Maloney, Risko, Ansari, and Fugelsang (2010) carried out an experiment to study the possibility that the complex-math deficits observed in HMA individuals might arise due to deficits in low-level numerical processing skills. To this end, they tested participants using a visual enumeration task involving sets of squares. Two distinct patterns of performance are considered to emerge in this kind of task: First, subitizing, which is shown when one to four elements have to be enumerated, and which is characterized by fast and accurate performance, showing a small increase in RTs and typically no decrease in accuracy as the number of stimuli presented increases; second, counting, which is used when five or more elements are presented and is characterized by an increase in RTs and a decrease in accuracy as the number of elements increases. Moreover, these two processes are considered to differentially tap WM, with counting making greater demands than subitizing (Tuholski, Engle, \& Baylis, 2001). Maloney et al. (2010) found that HMA individuals did not differ in subitizing but performed significantly worse in the counting range (5-9), as compared with LMA participants. According to these authors, this finding argued against the anxiety-complexity effect proposed by Ashcraft and colleagues, given that math-anxious groups differed in a task as simple as enumerating the quantity 
of stimuli presented. ${ }^{1}$ On the other hand, Maloney et al. (2010) also included participants' WM capacity (measured with backward digit span and backward letter span tasks) as a covariate, and found that the Group $\times$ Number interaction was no longer significant, suggesting that group differences in WM capacity were probably mediating the group effect on performance. Consequently, Maloney et al. (2010) suggested that the effect of MA might involve a lower-level deficit in numerical processing and that the anxiety-induced WM reduction would play a secondary role by serving to further exacerbate the effects of low-level deficits.

In a subsequent study (Maloney, Ansari, \& Fugelsang, 2011), the same research group performed another experiment in order to further investigate a possible deficit in numerical magnitude representation in HMA individuals, but this time by means of two numerical comparison tasks: one in which participants had to compare a number with a standard (i.e., lower/higher than 5), and another in which they had to compare two digits presented simultaneously (i.e., 38 ; which is the largest?); the latter is considered to involve fewer WM resources than the former, given that there is no standard to keep in mind. In order to assess how precise the participants' representations of numbers were, Maloney and collaborators (2011) analyzed the numerical distance effect, consisting in participants being faster and more accurate when the distance between the two numbers to be compared increased (e.g., it is easier to compare 2 vs. 9 than to compare 6 vs. 8). This effect is considered to reflect the relative overlap of numerical magnitude representations on the mental number line (Dehaene, 1997) and has been associated with variability in mathematical skills (Holloway \& Ansari, 2009).

Maloney et al. (2011) found that for both types of numerical comparison task, the effect of numerical distance on RTs was larger for HMA than for LMA individuals (i.e., HMA individuals needed more time as the distance between numbers was reduced, as compared with the LMA participants). Thus, while their previous study found (according to the authors) evidence opposing the complexity hypothesis, this subsequent one cast doubts on the role of WM and suggested that a less precise representation of numerical magnitude might play a role in MA. Indeed,

\footnotetext{
${ }^{1}$ The question, however, is how to differentiate between simple and complex arithmetic. Where is the line dividing them? Thus, although counting can be considered, a priori, to be a quite simple task, the fact that it requires more WM resources than does subitizing (Tuholski et al., 2001) might be enough to consider it as being more complex. In this sense, the fact that differences between math-anxious groups emerged for the complex task (i.e., counting; more WM demanding) but not for the simple one (i.e., subitizing; less WM demanding) could indeed give support to the anxiety-complexity effect proposed by Ashcraft and colleagues.
}

Maloney and collaborators (2011) proposed that a hybrid theory might best explain the phenomenon of MA: HMA individuals might suffer from a low-level numerical deficit that would form the basis of their difficulties with more complex mathematics. These math difficulties, in turn, would result in WM-demanding ruminations when they performed math tasks, which would exacerbate the initial difficulties they experienced.

A very recent study aimed to further investigate this claim of a less precise representation of numerical magnitude in HMA individuals by means of the ERP technique, by analyzing both size and distance effects (Núñez-Peña \& SuárezPellicioni, 2014). To this end, two groups extreme on math anxiety (assessed using the sMARS; Núñez-Peña, SuárezPellicioni, et al., 2013) were given a numeric comparison task, in which pairs of single-digit Arabic numbers were presented; the participants' task was to report the side of the screen (left or right) where the number of higher numerical magnitude had appeared. Núñez-Peña and Suárez-Pellicioni found that both the size and distance effects were larger for the HMA group than for their LMA peers: HMAs needed longer to respond to large numbers (e.g., 8 and 9) than to small ones (e.g., 1 and 2) (larger size effect), and they also needed more time to respond to numbers that were close to one another (distance 1; e.g., 8 and 9) than when they were more separated (distance 7; e.g., 2 and 9) (larger distance effect). As for the ERPs, the authors analyzed a P2 component, the amplitude of which is considered to be sensitive to the distance between two numbers to be compared, and therefore to be a good marker of the approximate numerical magnitude processing. Núñez-Peña and SuárezPellicioni found a P2 component of larger amplitude for the HMA group than for their LMA counterparts for both the distance and size effects. This study was therefore the first to provide psychophysiological evidence for a less precise representation of numerical magnitude in individuals high in math anxiety.

However, it should be noted that although Maloney and colleagues (2011) and Núñez-Peña and Suárez-Pellicioni (2014) interpreted the numerical distance effect as showing the acuity of numerical representation, this is not the only interpretation of the effect, since it has also been suggested that it can be accounted for by response selection processes (Banks, 1977; Van Opstal, Gevers, De Moor, \& Verguts, 2008). According to this view, the numerical distance effect in comparison tasks is due to the monotonic connection weights (for a more detailed explanation, see Verguts, Fias, $\&$ Stevens, 2005), given that, as the numbers become closer, the activation of the correct output node decreases, thus increasing RTs. According to this alternative interpretation, HMA individuals would have shown difficulties in selecting the correct response when the two numbers were closer, and thus would have differed from their 
LMA peers in response selection but not in their representation of numerical magnitude. ${ }^{2}$

\section{Math anxiety as an inhibition/attentional-control deficit}

Hopko and colleagues were the first to question whether susceptibility to distraction among HMA individuals might underlie the negative effects of disruptive thinking on WM, as was proposed by Ashcraft and collaborators. To this end, Hopko, Ashcraft, Gute, Ruggiero, and Lewis (1998) presented paragraphs for oral reading to participants classified as being low, medium, and high math-anxious. The task for participants consisted in reading aloud the italicized parts of paragraphs, which could be math-related or neutral, while trying to ignore the nonitalicized parts of the text, which could be either words (experimental condition) or a string of Xs (control condition) embedded as distractors within the paragraph. The words used in the experimental condition included both neutral (i.e., words unrelated to the paragraph content) and mathrelated (i.e., math words that were also unrelated to the paragraph content) distractors. After reading, participants were asked a series of questions in order to assess their level of comprehension of the paragraph content. Hopko and collaborators (1998) found that although all participants had slower reading times when words (rather than Xs) were embedded in the text (regardless of whether or not the word was math-related), the increase in reading times was particularly strong for the high and medium math-anxious groups. However, the additional time that these groups took to read the paragraphs was spent not on improving their memories (the groups scored fairly similarly on the comprehension test) but, it was postulated, on reading the nonitalicized parts of the text (which should be ignored). In light of these results, the authors suggested a modification of Ashcraft and colleagues' account by claiming that it would be more accurate to implicate a failure to inhibit attention to these thoughts as the key to understanding the relationship between worrying thoughts and the reduction in WM resources (Hopko et al., 1998).

In a later study, Hopko, McNeil, Gleason, and Rabalais (2002) formed two groups that were extreme in MA (top and bottom $20 \%$ of the distribution) and administered a card version of the numeric Stroop task, in which participants were told to state the quantity of numeric and nonnumeric (i.e., letter) stimuli (e.g., 222222, correct answer: six) while avoiding the interference of numeric identity. In this respect, the Stroop task has traditionally been used to measure the

\footnotetext{
${ }^{2}$ Consequently, if we consider this alternative explanation of the results obtained by Maloney et al. (2011), their findings would be further evidence in support of the attentional-control-deficit account of MA (see the next section), since response selection is considered to rely on the dorsolateral prefrontal conrtex (Rowe, Toni, Josephs, Frackowiak, \& Passingham, 2000), a key brain area for attentional control.
}

inhibition function, given that it requires the ability to focus attention on relevant information and inhibit that which is irrelevant. By means of the numeric version of the Stroop task, Hopko et al. (2002) found that the HMA group took significantly longer to respond to numeric than to nonnumeric stimuli, whereas the LMA group showed no differences in this respect. They interpreted this finding as evidence of the difficulty that HMA individuals have in the dual task of inhibiting attention to the magnitude conveyed by the numeric stimuli while simultaneously attending to their quantity. In short, they suggested that math-anxious individuals may possess a more trait-like inability to suppress attention to distracting information, a deficit that would not be dependent on exposure to numerical content.

In a more recent study, Suárez-Pellicioni, Nuñez-Peña, and Colomé (2014) used ERPs to explore in greater depth the previously reported inhibitory deficit in HMA individuals. To this end, they formed two groups extreme on MA (using the sMARS test; Núñez-Peña, Suárez-Pellicioni, et al., 2013) and administered a numerical Stroop task in which participants had to respond to the number of greater numerical magnitude, while avoiding the influence of the distracting dimension of the stimulus, its physical size. ${ }^{3}$ By using the ERP technique to study how HMA individuals process conflicting stimuli (i.e., incongruent trials) as opposed to nonconflicting ones (i.e., congruent ones), these researchers expected to obtain more specific information about possible differences between math-anxious groups in the different stages of conflict processing. More specifically, they measured an N450 component, linked to conflict detection, and a subsequent conflictsustained potential (hereinafter, conflict-SP), linked to the processes that take place in order to overcome conflict. They then performed two different analyses: conflict monitoring, calculating difference waves by subtracting the congruent condition from the incongruent one, and conflict adaptation, calculating the same difference waves, but separately for those trials preceded by congruence and those preceded by incongruity.

This study by Suárez-Pellicioni et al. (2014) reproduced previous findings showing a greater level of interference in RTs for HMA individuals as compared with LMA ones, suggesting once again that the former had difficulties in inhibiting attention to the irrelevant dimension of the task. Regarding ERPs, no significant differences were obtained for the conflict-monitoring analysis. However, the conflict adaptation analysis showed that whereas for the LMA group showed no differences for the conflict-SP with regard to the congruence

\footnotetext{
${ }^{3}$ It should be noted that the tasks used by Suárez-Pellicioni and colleagues (2014) and Hopko and colleagues (2002) differed from the ones used by Maloney and colleagues (2011): Where the former two groups of researchers used simple tasks involving the inhibition function, the latter used tasks involving basic numerical magnitude representation without inhibitory requirements.
} 
of the previous trial, the HMA group presented a greater conflict-SP for interference preceded by congruence than by incongruence. Given that this component has been considered to reflect the execution of top-down control (Larson, Kaufman, \& Perlstein, 2009), the authors interpreted their results as showing a proactive execution of attentional control after conflict detection in the LMA group, as compared with a reactive execution in the HMA group, a conclusion that is in line with previous claims and results for other types of anxiety (see Braver, Gray, \& Burgess, 2007; Fales et al., 2008; Osinsky, Gebhardt, Alexander, \& Hennig, 2012). In other words, they claimed that whereas LMA individuals would have exerted attentional control in a sustained way, the HMA group would have exerted attentional control in a transient way-that is, only when conflict was encountered in processing (i.e., only after incongruent trials). In short, given that the reactive recruitment of attentional control is considered to lead to greater vulnerability to distraction, they suggested that the greater interference experienced by HMA individuals in Stroop-related tasks may be related to the reactive way in which they exert attentional control.

It should be noted that although Suárez-Pellicioni et al. (2014) replicated the greater vulnerability to distraction found by Hopko and colleagues (2002) in the numerical Stroop task, they did not interpret this finding in the same way. Hopko and colleagues (2002) interpreted their findings in the context of PET (Eysenck \& Calvo, 1992), which was the prominent theory explaining the negative effects of anxiety on performance at the time they conducted their research. Subsequently, however, PET began to be questioned, mainly for lacking precision and explanatory power. For example, the notion that anxiety impaired the processing efficiency of the central executive of WM was considered to be imprecise because it did not specify which central executive functions were most adversely affected by anxiety. Similarly, although several studies had shown greater distractibility in high-anxious individuals (Eysenck, 1992; Eysenck \& Byrne, 1992), no theoretical assumptions within PET could account for these findings. As a result, PET (Eysenck \& Calvo, 1992) was reformulated into what became known as attentional-control theory (Eysenck, Derakshan, Santos, \& Calvo, 2007; hereinafter, ACT), which extended the scope of its predecessor while also being more precise as to the effects of anxiety on the functioning of the central executive of WM. Subsequent articles on MA, such as those by Suárez-Pellicioni and colleagues, were based on ACT.

According to ACT, the specific function of the WM central executive that is affected by (general) anxiety is attentional control, with anxiety causing an imbalance between the stimulus-driven attentional system (bottom-up) and the goal-directed attentional system (top-down). Consequently, highanxious individuals would be more influenced by the stimulus-driven attentional system, which would make them more vulnerable to bottom-up attentional intrusions - in other words, more vulnerable to distraction. By contrast, the same individuals would be less influenced by the goal-directed attentional system, which would make it difficult for them to focus on task objectives, thus increasing, again, the influence of distractors. In this respect, whereas PET had argued that anxiety impairs processing efficiency or performance because it produces worrying thoughts, in ACT this explanation is subsumed within a broader conceptualization, according to which anxiety impairs the inhibition function: Anxious individuals are more distracted by task-irrelevant stimuli, regardless of whether these stimuli are external (i.e., conventional distractors) or internal (i.e., worrying thoughts, ruminations, etc.).

\section{Origins and maintenance of MA}

Several studies have reported that MA emerges very early in childhood (Krinzinger et al., 2009; Ramirez et al., 2013; Thomas \& Dowker, 2000; Wu et al., 2012), it being already present in children in first through third grade (i.e., 6-9 years old).

The question, however, is why young children develop MA. How is it maintained? To date, the majority of studies have focused on environmental exposure to failure in mathematics as a potential primary mechanism for MA development (Ashcraft et al., 2007; Bekdemir, 2010; Meece, Wigfield, \& Eccles, 1990). However, more recent studies have pointed to other factors that may also play a role, such as a low level of math ability, an attentional bias, WM capacity, an abnormal response to errors, or genetic factors.

\section{Environmental factor}

Ashcraft, a pioneer in research on MA, noted that several of his participants reported that public embarrassment in math classes contributed to the development of their anxiety toward math (Ashcraft, 2002). Similarly, Bekdemir (2010) found that among preservice teachers, those who reported bad experiences in the math classroom were the ones who showed a higher level of MA, as compared with those teachers reporting no negative experiences. This finding suggests that negative events associated with math (e.g., instructors' hostile behavior, peer pressure, the inadequacy of instructors, etc.) may be directly related to the origins of this type of anxiety.

In relation to negative experiences with math, the role of teachers seems to be key. Turner and collaborators (2002) claimed that teaching based on high demand for correctness but providing little cognitive or motivational support may lead to avoidance on the part of students (Turner et al., 2002), 
which may constitute a risk factor in the development of MA. Another important aspect in this regard is teachers' own level of MA and the effect that this may have on students' learning and performance. In this respect, a moderate negative correlation has been found between teachers' level of MA and math teacher efficacy, it being shown that the preservice teachers with the lowest degree of MA had the highest levels of math teacher efficacy (Swars, Daane, \& Giesen, 2006).

Moreover, teachers have also been considered to be one of the paths through which negative gender stereotypes can be endorsed. Gender stereotypes seem to critically affect the performance of female students. For example, Beilock, Rydell, and McConnell (2007) tested two groups of women on a multistep mathematics problem and found that the stereotype threat group, which was told that the task was being used to investigate why women do worse than men in mathematics, showed worse performance than the control group, which was told that the researchers were studying problem solving. In this respect, it has been suggested that simply asking women to identify their gender before a math test can induce stereotype threat in them (Stricker \& Ward, 2004).

In a similar vein, Beilock, Gunderson, Ramirez, and Levine (2010) carried out a study to investigate the effect of teachers' own level of MA on students' math learning by measuring students' beliefs about gender and academic success in mathematics and the extent to which they adhered to traditional gender stereotypes (e.g., boys are good at math and girls are good at reading). They also assessed the levels of MA of 17 firstand second-grade female teachers and the math achievement of their students at the beginning and end of the course. They found that by the end of the school year, the more anxious that teachers were about math, the lower the math achievement in girls who had reported traditional ideas on gender abilities (this relationship was nonsignificant at the beginning of the school year; Beilock et al., 2010). The authors concluded that in early elementary school, teachers' MA had negative consequences for girls' math achievement by influencing their beliefs about who is good at math.

In addition to teachers, parents can also extend gender stereotypes to their children by expressing ideas such as "math is more difficult for girls" or "boys do best on math." These kinds of messages can negatively affect girls' attitudes toward math and, especially, their beliefs about their ability to do math (Goetz, Bieg, Lüdtke, Pekrun, \& Hall, 2013), with the corresponding effects on performance. In this respect, this gender stereotype about women's abilities with math content, exerted by parents, teachers, and others, might be responsible for the overall higher levels of MA reported by females ${ }^{4}$ as compared with males (Hembree, 1990).

Apart from the role of gender, it is known that, in general, a child's attitude toward mathematics can be considerably influenced by the parents' attitudes toward this subject. More specifically, it has been shown that parental beliefs about a child's math abilities are related to this child's math self-efficacy beliefs and performance level (Eccles, Jacobs, \& Harold, 1990). In this respect, parents' negative attitudes toward math and low expectations of their child's abilities with math can contribute to the development of MA in their young children, by "transferring" to them this negative conception of math and by making them question their own abilities to do math, negatively impacting their self-concept and self-efficacy beliefs.

However, parents can also exert a positive effect on their children's MA. In this respect, there is considered to be a general link between parenting practices and children's anxiety-related behaviors (McLeod, Wood, \& Weisz, 2007), with parental involvement playing an important role in young children's school success (Jeines, 2003). In the field of MA, Vukovic, Roberts, and Wright (2013) carried out a study assessing the relationship between parental involvement and children's math achievement, paying special attention to MA as a mediating factor. They found that parental involvement (home support and expectations for mathematics) influenced children's performance on higher levels of math (word problem solving, pre-algebraic reasoning, geometry, data analysis, and probability) by reducing their level of MA, thus suggesting that MA served as a mediator specifically for higher-order domains of mathematics.

\section{Genetic factor}

Ashcraft et al. (2007) speculated that MA was influenced by a complex interplay among several factors, which included a biological predisposition toward anxiety. Their guess was supported by a very recent study investigating the genetic and environmental factors contributing to MA in monozygotic and same-sex dizygotic twins. Wang et al. (2014) found that the development of this anxiety may involve not only exposure to negative experiences with math but also genetic risk factors, which accounted for roughly $40 \%$ of the variation in MA. More specifically, a more in-depth analysis showed that MA was influenced by the genetic and nonfamilial environmental risk factors associated with general anxiety and by

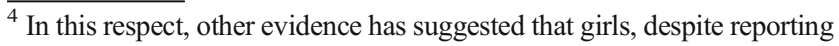
higher levels of trait MA, did not experience more state MA than boys, suggesting that the relationship between MA and gender is, in fact, nonexistent (Goetz et al., 2013). On the other hand, other researchers have suggested that the relationship between MA and gender is mediated by factors such as test anxiety (Devine, Fawcett, Szücs, \& Dowker, 2012) or spatial ability (Maloney et al., 2012).
} 
additional, independent genetic influences associated with math-based problem solving. In short, the authors claimed that genetic risks underlying poor math ability and general anxiety may predispose children to the development of MA.

\section{An initial low level of math ability}

As we mentioned above, MA is considered to negatively affect the level of performance of math tasks in those individuals who suffer from it. However, might it not be the case that MA is due to an initial low level of math ability? In this respect, a study aiming to determine the causal ordering between MA and math ability showed, by means of structural equation modeling, that prior low math achievement appeared to cause later high MA across the entire junior and senior high school grades, whereas prior high MA hardly ever caused later low math achievement (Ma \& Xu, 2004).

More specifically, two different abilities - discussed in the following two subsections - have been claimed to be impaired in HMA individuals, and therefore, might play a role in the origin of MA.

\section{Problems with domain-general abilities}

It has been suggested that intellectual aspects such as poor abstract thinking or visuospatial processing may contribute to the development of MA (Eden, Heine, \& Jacobs, 2013). In this respect, a very recent study showed that individuals high in MA reported a worse sense of direction and performed worse on behavioral tests of small- and large-scale spatial skills (Ferguson, Maloney, Fugelsang, \& Risko, 2015). Similarly, Maloney, Waechter, Risko, and Fugelsang (2012) found that sex differences in MA were mediated by spatial processing abilities. More specifically, they suggested that poor spatial abilities can constitute an obstacle to achievement in math, so children with poor spatial abilities would be more likely to experience negative experiences with math than would their peers with better spatial abilities, highlighting for the first time the possible role of this ability in the development of MA.

\section{Problems with "number sense"}

As was commented above, Maloney and colleagues (2011) proposed that HMA individuals are characterized by problems with "number sense" (Dehaene, 1997), which would manifest as less precise representations of numerical magnitude. Thus, they proposed that a deficit in this very basic numerical ability could be at the base of MA development, compromising the development of a higher level of mathematics.

Conversely, other researchers have claimed that there is no compelling evidence that poor performance causes MA, given that the relationship between MA and math ability (as well as between MA and IQ) is small, and that special work to enhance students' competence in math failed to reduce their levels of MA (Hembree, 1990). In a similar vein, Eden, Heine, and Jacobs (2013) claimed that the lack of significant correlations between MA and math performance in young populations (e.g., Krinzinger, Kaufmann, \& Willmes, 2009; Thomas \& Dowker, 2000) might indicate that MA cannot be a consequence of poor math ability (since otherwise they would cooccur, and a correlation would be found). Indeed, Eden et al. argued that this lack of correlation shows, in all likelihood, that MA leads to a low level of math performance and not the other way around, which would be in line with what Ashcraft and Faust (1994) claimed, whereby global avoidance would be the mechanism responsible for leading from initial MA to consequent low math performance on standardized tests.

To complete the picture regarding the relationship between these variables, it should be noted that it has also been claimed that the negative relationship between MA and low math performance might not exist, given that low scores on math performance are usually obtained through time-limited tests, situations in which the effects of MA on performance are more negative, and hence HMA individuals' scores on math ability assessments would indeed be underestimates of their true ability to perform math tasks (Ashcraft \& Moore, 2009).

\section{A high level of WM capacity}

As we commented above, the initial explanation of MA claimed that WM was the primary contributor to HMA individuals' performance deficits (Ashcraft \& Kirk, 2001). According to this account, MA produces a transitory disruption of WM, which is why the negative effects of performance would be shown only for those tasks relying on those WM resources (i.e., complex tasks). However, recent evidence obtained with 6- to 8-year-old children has shown that the negative relationship between MA and math achievement was present only for those children showing high WM capacity, as compared with their lower-WM-capacity peers (Ashcraft \& Kirk, 2001). The authors explained their findings as suggesting that higher-WM individuals might be more prone to poor performance as a function of MA because they would rely heavily on problem-solving strategies that load WM (e.g., direct retrieval, which requires retrieving facts from longterm memory and inhibiting competing answers). Conversely, lower-WM individuals, using less sophisticated (and less WM-demanding) problem-solving strategies (e.g., finger counting), would have little to lose through the depletion of WM resources by MA (Ramirez et al., 2013). Interestingly, the authors highlighted that, paradoxically, the students with greater potential for high math achievement (those with high WM capacity) are also the ones more susceptible to the deleterious effect of MA. 


\section{Attentional bias toward math-related information}

Given that it is a type of anxiety, MA may develop or be maintained through the same mechanisms as are general anxiety and other specific types of anxiety. Research on the etiology and maintenance of anxiety disorders has assigned a prominent role to attentional bias toward threat-related information (Mathews \& MacLeod, 2002). More specifically, this bias can be defined as a differential attentional allocation toward threatening stimuli, relative to neutral stimuli (Bar-Haim, Lamy, Pergamin, Bakermans-Kranenburg, \& van IJzendoorn, 2007; MacLeod, Mathews, \& Tata, 1986), and it has traditionally been measured by means of the emotional Stroop task (Williams, Mathews, \& MacLeod, 1996). On the basis of the original color conflict effect described by Stroop (1935), the emotional version of this task involves the presentation of emotionally charged or threatening words in different colors, with the task for participants being to report the presentation color of that word. An emotional Stroop effect is shown when the participant takes significantly longer to color-name words specific to his or her pathology or concerns, as compared with neutral control words. This emotional Stroop effect is considered to index the extent to which participants' attention is biased toward processing the content of words at the expense of solving the task (i.e., reporting the presentation color of these words).

To date, three experiments have sought to investigate whether HMA individuals are characterized by an attentional bias toward math-related information. McLaughlin (1996) was the first to use an emotional Stroop task including mathrelated and neutral words. The fact that this study showed no increase in RTs to math-related words for HMA individuals probably came about because the sample did not include groups presenting extreme levels of MA (the groups were formed using a split-half procedure, based on participants' mean MA), or because a paper version of the task was used. A second study carried out by Hopko, McNeil, Gleason, and Rabalais (2002) used the same task and materials as McLaughlin, but introduced certain innovations: First, these authors used a computer version of the task, which was considered to be a more powerful way of assessing interference than was the paper version (MacLeod, 1991), and second, they formed groups to be extreme in their MA scores (top and bottom $20 \%$ ). Despite these modifications, they still found no evidence of an emotional Stroop effect among HMA individuals. However, they acknowledged that their study might have had some methodological limitations (e.g., response latencies were calculated for 100 words that appeared together on the same screen; the kind of words used, such as polynomial and theorem, was probably too abstract and, therefore, less familiar to HMA individuals).

More recently, a third study on the question of attentional bias was conducted by Suárez-Pellicioni, Nuñez-Peña, and
Colomé (under review), who sought to overcome the abovementioned methodological shortcomings. In addition to maintaining the modifications introduced by Hopko et al. (2002) in their study, these researchers incorporated three new ones: Words were presented individually, they were significantly related to mathematics for the participants involved, ${ }^{5}$ and several subject variables, such as trait anxiety, were controlled. Differences between math-anxious groups did finally emerge, showing that HMA individuals needed longer to report the color of math-related words as compared with neutral words, whereas no such difference emerged for their LMA counterparts. According to the interpretation of the emotional Stroop effect, HMA individuals' attention would have been directed to processing the content of the math-related words, thus distracting them from the main task of reporting the words' color. Given that an attentional bias toward threatening information has been considered a cognitive marker of numerous types of anxiety (Bar-Haim et al., 2007), playing an important role in anxiety's origin and maintenance (Beck, Emery, \& Greenberg, 1985), attentional bias toward mathrelated information could also be a possible mechanism by which MA might originate and be maintained and/or aggravated.

\section{Abnormal processing of numeric errors}

In a recent study, Suárez-Pellicioni, Núñez-Peña, and Colomé (2013b) explored differences in error processing between LMA and HMA individuals by means of the ERP technique. These authors formed two groups according to the participants' levels of MA and then administered both a numeric version of the Stroop task, in which participants had to report the numerical magnitude of the digit while ignoring its physical size (e.g., 2 8), and a classical version of the Stroop task (control task), in which the Spanish words rojo, verde, and azul (i.e., "red," "green," and "blue," respectively) were presented in either red or green and the task for participants was to report the presentation color. The researchers analyzed the electrophysiological correlate at the moment when the response was given, and compared the error-related negativity (ERN), an ERP component that appears $50 \mathrm{~ms}$ after error commission, between groups and for each task. They found that this component showed enhanced amplitudes for errors committed in the numeric task as compared with the classical one, but only for the HMA group; there were no differences between the tasks for the LMA group. Suárez-Pellicioni et al. (2013b) also used standardized low-resolution

\footnotetext{
${ }^{5}$ The words were obtained through a questionnaire asking psychology undergraduates $(n=117)$ to write down the first 15 words that came to mind when thinking about mathematics. From this information, the 14 words that were most reported by students as being math-related were selected for the experiment.
} 
electromagnetic tomography (sLORETA) to determine the brain electrical sources of this component, and found a greater involvement of the right insula for errors committed in the numeric as compared with the nonnumeric task in the HMA group, but no differences for the LMA participants. Given that the ERN has been interpreted as indicating the significance of and emotional reaction to errors and has shown greater amplitude in several anxious samples (e.g., Gehring, Himle, \& Nisenson, 2000; Weinberg, Olvet, \& Hajcak, 2010), and also considering the greater insular involvement for numerical errors, the authors concluded that HMA individuals showed a greater emotional response to self-committed errors in a task involving numbers, as compared with a neutral one. All of us have committed numerous errors in math, and all of us have learned from them. However, if an individual with a tendency to be HMA has a negative emotional reaction every time he or she fails, this will only contribute to the development of negative attitudes toward math and encourage the avoidance of math-related contents/situations, factors that then serve to consolidate the anxiety experienced therein.

\section{MA and the brain}

Although the bulk of early research on MA had used behavioral measures to test hypotheses (i.e., RTs, error rates, and flawed scores), Ashcraft and Ridley (2005) suggested that investigating the neural regions that are active when HMA and LMA individuals perform a math task, especially in combination with parallel tests on nonmathematical stimuli, would be enormously useful (Ashcraft \& Ridley, 2005). Following this suggestion, recent research has incorporated new techniques, such as ERPs, in order to obtain more sensitive measurements of the timing of math-related processes, whereas fMRI has been used to identify the brain areas involved in them.

Young, Wu, and Menon (2012) used fMRI to analyze the brain activity of 46 seven- to nine-year-old students with different levels of MA while they performed an addition and subtraction verification task. Young et al. found that at these early ages, MA was associated with hyperactivity of the right amygdala, which was observed in conjunction with lower problem-solving accuracy. The amygdala is known to play an important role in normal fear conditioning (LeDoux, 2000) and in the pathophysiology of anxiety disorders (Rauch, Shin, \& Wright, 2003). For example, amygdala hyperactivity to emotional human faces has been demonstrated in social anxiety disorders (Birbaumer et al., 1998) and in posttraumatic stress disorder (Rauch et al., 2000).

Young et al. (2012) also found that MA was associated with abnormal effective connectivity of the amygdala, specifically in the form of both greater effective connectivity with the ventromedial prefrontal cortex region, an area related to the regulation of negative emotions, and less effective connectivity with the posterior parietal cortex (e.g., intraparietal sulcus, superior parietal lobule, and angular gyrus), important for mathematical processing. The greater effective connectivity between the right amygdala and the ventromedial prefrontal cortex in HMA children was interpreted as facilitating compensatory mechanisms that would allow children with HMA to perform well, albeit at a lower level than LMA children.

Other research groups have also investigated the brain correlates of the anxious reaction toward mathematics. For example, Lyons and Beilock (2012a) formed two groups according to participants' levels of MA and then administered a mental arithmetic task and a control task (word verification), matched in difficulty, during fMRI data acquisition. Before each set of problems, individuals were presented with a cue (i.e., a simple colored shape) that identified the upcoming task (either math or control). Lyons and Beilock (2012a) argued that this would allow them as researchers to separate the effects of math (i.e., performance in a math task) from the effects of anxiety (i.e., anticipation of a math-related task). They found that when participants anticipated an upcoming math task, the higher their level of MA, the greater the activity in the bilateral dorsoposterior insula, an area associated with visceral threat detection and with the experience of pain; by contrast, these areas showed no significant activation during math task performance (Lyons \& Beilock, 2012a). ${ }^{6}$ The authors interpreted this finding as showing that the anticipation of a math task was perceived as a painful event in the brains of HMA individuals. In a similar vein, Suárez-Pellicioni et al. (2013b) also found greater involvement of the right insula for numeric than for nonnumeric errors in HMA individuals when they analyzed the electrical brain sources (sLORETA) of the ERN, an ERP component that showed greater amplitude for the task involving numbers than for the control task.

Although the insula has frequently been associated with disgust (Phillips et al., 2004) and pain (Isnard, Magnin, Jung, Mauguière, \& Garcia-Larrea, 2011), there is increasing evidence of a broader role for this brain structure in emotional processing (Phan, Wager, Taylor, \& Liberson, 2002), as well as sound evidence for its involvement in anxiety disorders (e.g., Paulus \& Stein, 2006). For example, symptom provocation in individuals with obsessive-compulsive disorder, simple phobia, or posttraumatic stress disorder has been shown to be associated with increased cerebral blood flow in bilateral insular cortex (Rauch, Savage, Alpert, Fischman, \& Jenike, 1997), whereas the right insula has been found to show an

\footnotetext{
${ }^{6}$ Interestingly, previous studies have also reported insular hyperactivation in socially anxious patients during anticipation of speech, as compared with a control condition (Boehme et al., 2014), in the same way that Lyons and Beilock (2012a) found for HMA individuals when they were anticipating a forthcoming math task.
} 
exaggerated response to fearful faces in individuals with specific phobia (Wright, Martis, McMullin, Shin, \& Rauch, 2003).

In this context, the fact that MA activates brain areas linked both to fear processing (i.e., the amygdala) and to disgust and pain processing (i.e., the insula) suggests that this anxiety is grounded in an aversive bodily reaction, a clearly plausible mechanism to explain the origin of negative attitudes toward mathematics and the global avoidance tendency toward mathrelated content in HMA individuals.

Lyons and Beilock (2012b) registered brain activity while participants solved a numeric task (addition and subtraction verification) and a control (word verification) task. They observed that HMA individuals performed more poorly on the former than on the latter, whereas the LMA group showed no differences between tasks. More interestingly, they found that performance in the math task was predicted by neural activity in response to the cue (i.e., when anticipating the math task) in the network of inferior frontoparietal regions, and more specifically the bilateral inferior frontal junction (IFJ). The IFJ is coactivated with the dorsolateral prefrontal cortex (DLPFC) as part of a network associated with cognitive control, and, therefore, it is considered to play a crucial role in this function (Derrfuss, Brass, Neumann, \& von Cramon, 2005). Lyons and Beilock (2012b) interpreted their findings as evidence that some HMA individuals were able to overcome the attentional deficits that may have caused MA by ramping up control resources before the math task itself began. Thus, they concluded that the extent of HMA individuals' deficits in mathematics can be predicted by how cognitive control resources are recruited before doing math.

Finally, Young et al. (2012) also found that, in addition to amygdala hyperactivity, HMA individuals showed reduced activity in the DLPFC when performing an addition and subtraction verification task, ${ }^{7}$ thus confirming that the brain substrate of the cognitive control function seems to show abnormal activity in HMA individuals.

It should be noted that the DLPFC is also thought to be involved in the online trial-to-trial adjustment of attentional control, which has been demonstrated through tasks such as the Stroop task by analyzing the level of interference as a function of the congruence of the previous trial (Vanderhasselt, De Raedt, \& Baeken, 2009). As we commented above, Suárez-Pellicioni et al. (2014) explored conflict adaptation effects in a numeric Stroop task and found amplitude differences for the HMA group in the conflict-SP, an ERP component appearing after conflictive stimuli that has been linked to the execution of top-down control (Larson

\footnotetext{
${ }^{7}$ Note that in the study by Lyons and Beilock (2012b), the IFJ showed increased activation before task performance (anticipation), whereas in the study by Young et al. (2012), the DLPFC showed reduced activation during task performance.
}

et al., 2009) and whose neural sources have been located in the lateral prefrontal cortex (LPFC; West, 2003). Consequently, their findings suggest that, whereas in the study by Lyons and Beilock (2012b) ramping up cognitive-control resources when anticipating a math task implied better performance in HMA individuals, their drop in performance in the numeric Stroop task can be attributed to their not exerting cognitive control after congruent trials.

In this line of research, Sarkar, Dowker, and Cohen Kadosh (2014) applied transcranial direct current stimulation (tDCS) to the DLPFC of LMA and HMA individuals in order to explore whether the stimulation of this control brain area would ameliorate the anxious response. They found that, after this stimulation, HMA individuals showed improved RTs on a simple arithmetic task and decreased cortisol concentrations (a biomarker of stress), suggesting that enhancing emotional control was related to better performance. All of these findings are in line with research on general anxiety claiming that anxiety impairs the recruitment of prefrontal mechanisms that are critical to the active control of attention (Bishop, 2009).

To sum up, research on the brain structures related to MA has revealed that this anxiety involves the same brain structures previously reported for other types of anxiety, including emotional brain areas such as the amygdala (e.g., Rauch et al., 2003) and the insula (e.g., Paulus \& Stein, 2006), as well as prefrontal areas (e.g., Bishop, 2009). Evidence regarding the brain substrates of MA therefore lend support to previous claims suggesting a common neurobiological pathway both for anxiety disorders (Etkin \& Wager, 2007), given that certain brain areas (i.e., amygdala, insula) are activated in several types of anxiety (i.e., posttraumatic stress disorder, social phobia, and specific phobia), and also for anxiety-prone individuals (Stein, Simmons, Feinstein, \& Paulus, 2007). Thus, MA, despite being a construct separate from trait anxiety, constitutes a specific anxiety that is elicited by numerical and mathrelated stimuli, and it relies on the same brain circuits involved in other types of anxiety.

\section{What can we do about it?}

The ultimate objective of research on MA should be intervention, seeking to prevent its development in young children and to reduce its negative consequences in those who already suffer from it. Considering that the level of MA tends to increase in severity in 5th through 12th graders over time (i.e., from 10 to 18 years old; Ma, 1999), the importance of early identification of this type of anxiety is indisputable. In this section, we offer a number of suggestions regarding how teachers, parents, and psychologists can contribute to this aim. 


\section{Some things teachers could do}

Given that negative experiences in math classrooms have been related to the origins of MA (Bekdemir, 2010), teachers should never be hostile toward or embarrass a student facing difficulties with mathematics. They should not allow other students to do this, either.

Environmental exposure to failure in math has also been described as a potential primary mechanism for MA development (Ashcraft et al., 2007). It is therefore important to prevent students becoming frustrated with mathematics by establishing progressive and feasible goals. In this respect, it would be advisable for teachers to support those students showing difficulties with math-for example, by making them feel comfortable when resolving their queries and encouraging them to ask for help any time they need it.

It has been suggested that MA does not derive from mathematics itself, but rather from the way math is presented in school and may have been presented to school teachers when they were students (Geist, 2010). In this sense, it has been suggested that MA could be transferred from anxious female teachers to their female students by influencing their beliefs about who is good at math (boys vs. girls; Beilock et al., 2010). Therefore, it is very important to reduce teachers' own level of MA in order to prevent any such transmission to their students, and also to work on dismantling possible stereotypes that teachers may have about gender differences in math competence.

Because of the great influence that teachers have on their students, especially at young ages, it is also very important to be careful with the kind of messages that students receive. For example, consolation messages such as "It's OK, not everyone can be good at these types of problems" (Beilock \& Willingham, 2014) may send out the wrong message, since it might be interpreted as "Maybe this math problem is too hard for you, given your low ability in math"; likewise, the message "Not everybody can be good at math" could be interpreted as "You're one of those people who is no good at math."

Teachers should try to prevent the development of negative attitudes toward mathematics in those students showing difficulties with math (Hembree, 1990), given that these attitudes may well be linked to the avoidance of math content (Lefevre et al., 1992). It would be important that they highlight the importance of mathematics, emphasizing the positive qualities that each student has in relation to the subject, giving positive feedback about correctly solved tasks and minimizing the importance of errors. Similarly, students should be encouraged to see that working hard on math is the only way of succeeding, since the latter does not depend on any special intellectual abilities or gifts.

Teachers should try to identify at-risk children in order to adapt classroom requirements and, especially, assessments to them. In this respect, short scales, such as the six-item ATMS (Sandman, 1980) or the nine-item AMAS (Hopko et al., 2003), are available for assessing students' levels of MA in the event that the time constraints frequently found in classroom settings make it impossible to administer more extensive scales (e.g., sMARS). Once students with a high level of MA have been detected, teachers should take into account that the effects of MA on performance have been shown to disappear when a task is performed without time pressure (Faust et al., 1996). It has also been suggested that the early use of highstress techniques such as timed tests, rather than more developmentally appropriate and interactive approaches, leads to a high incidence of MA (Geist, 2010). We acknowledge that a test cannot be completely time-unlimited, but our suggestion is that teachers promote their HMA students' performance by giving out such messages as "Don't worry if you don't finish in an hour, I can wait until you finish," or "Don't worry about time, you'll have all the time you need to finish the test."

Teachers should consider HMA individuals' greater vulnerability to distraction (Hopko et al., 1998; Hopko et al., 2002; Suárez-Pellicioni et al., 2013a, 2014), for example, when designing math textbooks. It would be recommendable to bear in mind that an excessive number of drawings or colors might have counterproductive effects on children with high levels of MA, by distracting their attention away from the math exercises.

Similarly, it is considered that distractibility is not limited to external stimuli, since internal stimuli such as worrying thoughts and ruminations may also distract students' attention from the main cognitive task. In this respect, Park, Ramirez, and Beilock (2014) have shown that writing before an exam has surprising positive effects on performance. They asked students to write freely about their emotions regarding an upcoming test (for $10 \mathrm{~min}$ ) and found that this writing helped reduce the gap between LMA and HMA students. Their interpretation of this result was that expressive writing reduced the likelihood that math-related worries would subsequently capture attention during the math task. This finding should be considered as a possible class intervention that teachers can apply in order to try to reduce the negative effects of MA on math test performance.

Faust (1992) found physiological evidence of increasing reactivity (i.e., changes in heart rate) when math-anxious individuals performed math tasks of increasing difficulty, but not for an increasingly difficult verbal task. It has been suggested that it is not the physiological reactions per se, but rather the interpretation of these reactions that determines emotions (Schachter \& Singer, 1962). In the field of MA, the interpretation of physiological responses in stressful situations has been found to determine whether these responses will be disruptive or beneficial to performance. MattarellaMicke, Mateo, Kozak, Foster, and Beilock (2011) found that the level of MA determined the relationship between salivary 
cortisol concentrations (a hormone associated with stressors in humans) and the level of performance in an arithmetic task (but only for individuals with high WM capacity; see "A high level of WM capacity" section above for an explanation): For HMA individuals, as the concentration of cortisol increased (i.e., greater physiological response), the level of performance decreased, whereas for LMA participants, their level of performance increased in line with the concentration of cortisol. These results were interpreted as showing the importance of a person's interpretation of physiological responses, since a negative interpretation would have led HMA individuals to perform poorly, whereas a positive (or at least nonthreatening) interpretation in their LMA peers appeared to have helped them succeed in the task. In this context, an interesting intervention was applied by Jamieson, Mendes, Blackstock, and Schmader (2010), who selected students who were preparing to take the Graduate Record Examination (GRE) and then collected saliva samples from them before and after they performed the GRE in a testing environment (lab test). Participants were assigned to one of two groups: a reappraisal group (which received a message that read that recent research had suggested that arousal does not hurt performance on tests, so people feeling anxious should not be concerned, given that this arousal could be helping them to perform well) and a control group (which received no message; Jamieson et al., 2010). The researchers found that participants in the reappraisal group exhibited a significant increase in salivary alpha amylase (a measure of sympathetic nervous system activation) and outperformed the controls on the GRE math section, both in the practice laboratory task and in the actual GRE. Teachers might find useful this knowledge in order to assess its effects on math performance in their own students.

\section{Some things parents could do}

Parents should be careful not to transmit their own level of MA to their children, which means paying attention to the kinds of messages they send. Messages such as "I've always found math difficult" or "I've never been a math person" can contribute to the development of negative attitudes toward this subject in their children.

Parents would be advised to talk about math in a positive way, to play math games with their children, and to highlight that math is very useful for everyday situations and that it can be fun.

Parents should not instill their children with myths about the difficulty of math ("Math is too hard for average people"), the need for special brain/genetic abilities in order to do math ("You are born with a math gene, either you have it or you don't"), or gender differences in math ability ("Boys are best at math").
Home support and expectations have been shown to be the main aspects of parental involvement when it comes to minimizing the negative effects of MA on performance (Vukovic et al., 2013). Thus, it is important for parents to know that they can help by supporting their children at home when they do their math homework or study for a math test. Similarly, it would be important for parents to feed children's selfconcept of math, highlighting their abilities to do well in math and expressing the positive results that parents expect from them.

\section{Some things psychologists could do}

The meta-analysis by Hembree (1990) showed that systematic desensitization, anxiety management, and conditioned inhibition training were highly successful in reducing levels of MA (e.g., Suinn, Edie, \& Spinelli, 1970) and increasing the level of math performance. By contrast, relaxation training or group discussion seem not to be effective. In any case, reductions of the levels of MA were obtained for individual trainings, whereas whole-class interventions showed unsuccessful results. Psychologists should keep working on designing further interventions that will improve upon the effectiveness of previous ones.

In line with previous claims that MA has to do with an attentional-control deficit, intervention programs aiming to improve this function in HMA individuals deserve special consideration. Recent evidence has shown that a short bout of focused breathing exercise can boost the performance of students with HMA when they attempt a high-pressure arithmetic task (Brunyé et al., 2013). According to these authors, the bout of focused breathing was able to train the effective control of attention away from the distressing feelings in HMA individuals and, consequently, to focus attention on mathematical operations.

Finally, new interventions have recently been developed that seek to decrease anxiety levels by reducing attentional bias toward threatening information. This approach, generally referred to as an attention bias modification program, is based on different modified versions of the dot probe task and aims to measure and manipulate attentional bias toward threatening information. The experimental results to date are very promising. It has been shown that training attention to be biased toward threat increases anxiety (MacLeod, Rutherford, Campbell, Ebsworthy, \& Holker, 2002), and that training attention away from threat can actually reduce symptoms of social phobia (Amir, Weber, Beard, Bomyea, \& Taylor, 2008) and generalized anxiety disorder (Schmidt, Richey, Buckner, \& Timpano, 2009), supporting the idea that attentional bias toward threat may be amenable to treatment. 


\section{Conclusions}

This review has considered a number of studies showing that several processes present in other types of anxiety can be extended to math anxiety. For example, HMA individuals show greater vulnerability to distraction (Hopko et al., 1998; Hopko et al., 2002; Suárez-Pellicioni et al., 2013a, 2014), a finding consistent with research on general anxiety (Eysenck, 1992; Eysenck \& Byrne, 1992), and they also seem to exert attentional control in a reactive way (Suárez-Pellicioni et al., 2014), as has previously been suggested for trait anxiety by studies using ERPs (Osinsky et al., 2012) and fMRI (Fales et al., 2008). Similarly, there is evidence that HMA individuals show abnormal error monitoring for numeric errors (Suárez-Pellicioni et al., 2013b), as was previously reported for several types of anxiety disorders (e.g., Gehring et al., 2000), as well as an attentional bias toward math-related information (Suárez-Pellicioni et al., under review), which may provoke and maintain this affective condition (McLeod et al., 2007; see Bar-Haim et al., 2007, for the same bias in other types of anxiety).

In addition to the above findings, the application of neuroscience methods to the study of MA has shown that its brain correlates are similar to those observed in general or in other types of specific anxieties - specifically, hyperactivity of emotional brain areas such as the amygdala (Young et al., 2012) or the insula (Lyons \& Beilock, 2012a; SuárezPellicioni et al., 2013b) and reduced activity of cognitivecontrol brain areas such as the DLPFC (Young et al., 2012) or the IFJ (Lyons \& Beilock, 2012b). The latter finding is consistent with one of the proposed explanations for MA, namely an attentional-control deficit, which would be responsible for HMA individuals' reduced ability to maintain stimulus, goal or contextual information in an active state when exposed to interference, and to effectively inhibit goalirrelevant stimuli and/or responses. In this respect, there is also evidence that HMA individuals find it difficult to resist the interference of distracting stimuli (i.e., large-split solutions; Suárez-Pellicioni et al., 2013a) or the distracting dimension of a stimuli (i.e., numerical magnitude in Hopko et al., 2002; physical size in Suárez-Pellicioni et al., 2014).

Despite the great advances made by recent research on MA, however, several aspects either need to be assessed for the first time or require further research. In general, future research needs to be targeted at studying how the different factors associated with the origin and maintenance of MA act and interact with one another, how negative these factors are if they are present alone, what their incremental negative effect might be when combined with other factors, at how early an age they might be observed, and so forth.

More specifically, and regarding the mechanisms that might play a role in the origin or development of MA, more research is required to clarify the nature of attentional bias in
MA, determining whether HMA individuals show facilitated engagement, difficulties with disengagement, or avoidance of math-related information. To this end, different attentional tasks, such as the dot probe task (Koster, Crombez, Verschuere, \& De Houwer, 2004) or the visual search task (Öhman, Flykt, \& Esteves, 2001), have been shown to be adequate for both assessing and modifying this bias (Hallion $\&$ Ruscio, 2011). In this respect, further research will be required to demonstrate the effectiveness of attentional bias modification programs in reducing MA.

Another factor mentioned as playing a role in the origin and development of MA is WM capacity. In this respect, two studies have reported surprising findings on the relationship between WM capacity and MA: Individuals with higher WM capacity have shown to be potentially more affected by the negative effects of MA (Ramirez et al., 2013), and also to be those for whom higher levels of MA implied a negative relationship between cortisol concentrations and performance (Mattarella-Micke et al., 2011). Given that these two studies explained their results in terms of the strategies used to solve the math tasks (more sophisticated for individuals with higher levels of WM, and more rudimentary for those low in this capacity), future research should investigate the differential use of strategies between LMA and HMA individuals and its relationship with participants' levels of WM capacity.

Regarding the complex relationship between MA and math ability, further research will be required with very young children, from a longitudinal perspective, in order to clarify whether an initial high level of MA results in a low level of math performance (Ashcraft \& Faust, 1994; Eden, Heine, \& Jacobs, 2013) or whether, on the other hand, an initial low level of math performance (i.e., math ability) is what leads to an increase in MA (Ma \& $\mathrm{Xu}, 2004)$.

As for the explanations of MA, recent studies in this regard have interpreted their results in the context of the ACT (Eysenck et al., 2007), claiming that anxiety reduces attentional control. Although, in the field of MA, several studies have pointed to an inhibition deficit in HMA individuals (Hopko et al., 1998; Hopko et al., 2002; Suárez-Pellicioni et al., 2013a, 2014), no study to date has shown the effects of MA on the other control function (Miyake et al., 2000) considered to be affected by anxiety: shifting. Shifting could be measured, for example, by a task in which two-digit numbers are presented and addition and subtraction are required to be performed alternately (Eysenck et al., 2007). Future research in this line would help to clarify whether or not these two processes (inhibition and shifting) are equally compromised, and to what extent.

Evidence regarding the brain substrates of MA suggests that, despite its being considered a separate construct from trait anxiety (Hembree, 1990), MA involves the same brain areas and emotional-processing circuits implicated in other types of anxiety (Etkin \& Wager, 2007). Thus, what would 
differentiate MA from other types of anxiety is the kind of stimuli that trigger the anxious reaction: Whereas social phobia is elicited by stimuli related to people, giving a speech, and so on, MA would be elicited by situations involving numbers and math tasks. In this respect, it would be of great interest to investigate the different types of stimuli/situations that might trigger the math-anxious reaction (math class, math test, math task, a single digit, the simple "+" sign, memories of a traumatic event, just thinking/imagining a situation, etc.), as well as their impacts on the brain when the person anticipates them (as in the study by Lyons \& Beilock, 2012a) and when they occur unpredictably.

Furthermore, to the best of our knowledge, no study to date has examined the emotional regulation strategies in HMA individuals and their neural correlates. Future research could study the use of these strategies depending on the level of MA, by using tasks in which participants are instructed to decrease their emotional responses by means of different strategies (distraction, reappraisal, etc.; see, e.g., Beauregard, Levesque, \& Bourgouin, 2001; Kalisch, Wiech, Herrmann, \& Dolan, 2006), and then analyze their brain correlates.

Finally, whereas the bulk of research on MA has been based on self-reported measures of trait MA (habitual anxiety), the effect of state MA (momentary anxiety) has barely been considered (e.g., Goetz et al., 2013). Future research should focus on the differential effects of trait and state MA on math performance and the brain correlates of each of them, given the important information this could provide in terms of designing intervention programs.

To conclude, the ultimate aim of research on MA should be to prevent children from developing MA, and also to reduce the high level of MA in those students who have already experienced its negative effects on their academic performance. To this end, it is important to bear in mind the multifactorial nature of its origin, such that any attempt to detect, assess, and intervene with MA must consider environmental (e.g., classroom context, peers, teachers, parents), cognitive (e.g., math ability), and personality (e.g., self-efficacy beliefs, regulation skills) variables. In this respect, although some researchers have started to explore possible ways of reducing the negative effects of MA on performance (Park et al., 2014; Sarkar, Dowker, \& Cohen Kadosh 2014), further efforts will be required in the form of intervention programs that can stop normally skilled individuals from avoiding math-related content because of their anxiety. Research of this kind would clearly be a valuable investment in both personal and socioeconomic terms.

Author note This research was supported by the Spanish Ministry of Economy and Competitiveness under Grant Number PSI2012-35703, the Spanish Ministry of Science and Technology under Grant Number BES2010-036859, and the Generalitat de Catalunya under Grant Number SGR2014-177.

\section{References}

Alexander, L., \& Martray, C. (1989). The development of an abbreviated version of the Mathematics Anxiety Rating Scale. Measurement and Evaluation in Counseling and Development, 22, 143-150.

American Psychiatric Association. (2000). Diagnostic and statistical manual of mental disorders (4th ed.). Washington, DC: American Psychiatric Association.

Amir, N., Weber, G., Beard, C., Bomyea, J., \& Taylor, C. T. (2008). The effect of a single-session attention modification program on response to a public-speacking challenge in socially anxious indiviuals. Journal of Abnormal Psychology, 11, 860-868. doi:10.1037/a0013445

Ashcraft, M. H. (2002). Math anxiety: Personal, educational, and cognitive consequences. Current Directions in Psychological Science, 11, $181-185$.

Ashcraft, M. H., \& Battaglia, J. (1978). Cognitive arithmetic: Evidence for retrieval and decision processes in mental addition. Journal of Experimental Psychology: Human Memory and Learning, 4, 527538. doi:10.1037/0278-7393.4.5.527

Ashcraft, M. H., \& Faust, M. W. (1994). Mathematics anxiety and mental arithmetic performance: An exploratory investigation. Cognition and Emotion, 8, 97-125.

Ashcraft, M. H., \& Kirk, E. P. (2001). The relationships among working memory, math anxiety, and performance. Journal of Experimental Psychology: General, 130, 224-237. doi:10.1037/0096-3445.130.2.224

Ashcraft, M. H., \& Krause, J. A. (2007). Working memory, math performance, and math anxiety. Psychonomic Bulletin \& Review, 14, 243 248. doi:10.3758/BF03194059

Ashcraft, M. H., Krause, J. A., \& Hopko, D. R. (2007). Is math anxiety a mathematical learning disability? In D. B. Berch \& M. M. M. Mazzocco (Eds.), Why is math so hard for some children? The nature and origins of mathematical learning difficulties and dissabilities (pp. 329-348). Baltimore, MD: Brookes.

Ashcraft, M. H., \& Moore, A. M. (2009). Math anxiety and the affective drop in performance. Journal of Psychoeducational Assessment, 27, 197-205.

Ashcraft, M. H., \& Ridley, K. (2005). Math anxiety and its cognitive consequences: A tutorial review. In J. I. D. Campbell (Ed.), Handbook of mathematical cognition (pp. 315-325). New York, NY: Psychology Press.

Banks, W. P. (1977). Encoding and processing of symbolic information in comparative judgments. In G. H. Bower (Ed.), The psychology of learning and motivation (pp. 101-159). New York: Academic Press.

Bar-Haim, Y., Lamy, D., Pergamin, L., Bakermans-Kranenburg, M. J., \& van IJzendoorn, M. H. (2007). Threat-related attentional bias in anxious and nonanxious individuals: A meta-analytic study. Psychological Bulletin, 133, 1-24. doi:10.1037/0033-2909.133.1.1

Beauregard, M., Levesque, J., \& Bourgouin, P. (2001). Neural correlates of conscious self-regulation of emotion. Journal of Neuroscience, 21, RC165.

Beck, A. T., Emery, G., \& Greenberg, R. L. (1985). Anxiety disorders and phobias: A cognitive perspective. New York, NY: Basic Books.

Beilock, S. L., Gunderson, E. A., Ramirez, G., \& Levine, S. C. (2010). Female teachers' math anxiety affects girls' math achievement. Proceedings of the National Academy of Sciences, 107, 1060-1063.

Beilock, S. L., Rydell, R. J., \& McConnell, A. R. (2007). Stereotype threat and working memory: Mechanisms, alleviation, and spillover. Journal of Experimental Psychology: General, 136, 256-276. doi: 10.1037/0096-3445.136.2.256

Beilock, S. L., \& Willingham, D. T. (2014). Math anxiety: Can teachers help students reduce it? American Educator, 38(2), 28-32, 43.

Bekdemir, M. (2010). The pre-service teachers' mathematics anxiety related to depth of negative experiences in mathematics classroom while they were students. Educational Studies in Mathematics, 75, 311-328. 
Birbaumer, N., Grodd, W., Diedrich, O., Klose, U., Erb, M., Lotze, M., . . . Flor, H. (1998). fMRI reveals amygdala activation to human faces in social phobics. NeuroReport, 9, 1223-1226.

Bishop, S. J. (2009). Trait anxiety and impoverished prefrontal control of attention. Nature Neuroscience, 12, 92-98. doi:10.1038/nn.2242

Boehme, S., Ritter, V., Tefikow, S., Stangier, U., Strauss, B., Miltner, W. H., \& Straube, T. (2014). Brain activation during anticipatory anxiety in social anxiety disorder. Social Cognitive and Affective Neuroscience, 9, 1413-1418. doi:10.1093/scan/nst129

Braver, T. S., Gray, J. R., \& Burgess, G. C. (2007). Explaining the many varieties of working memory variation: Dual mechanisms of cognitive control. In A. R. A. Conway, C. Jarrold, M. J. Kane, A. Miyake, \& J. N. Towse (Eds.), Variation in working memory (pp. 76-106). New York, NY: Oxford University Press.

Brunyé, T. T., Mahoney, C. R., Giles, G. E., Rapp, D. N., Taylor, H. A., \& Kanarek, R. B. (2013). Learning to relax: Evaluating four brief interventions for overcoming the negative emotions accompanying math anxiety. Learning and Individual Differences, 27, 1-7. doi:10. 1016/j.lindif.2013.06.008

Chiu, L. H., \& Henry, L. L. (1990). Development and validation of the Mathematics Anxiety Scale for Children. Measurement and Evaluation in Counseling and Development, 23, 121-127.

Dehaene, S. (1997). The number sense. New York, NY: Oxford University Press.

Derrfuss, J., Brass, M., Neumann, J., \& von Cramon, D. Y. (2005). Involvement of the inferior frontal junction in cognitive control: Meta-analyses of switching and Stroop studies. Human Brain Mapping, 25, 22-34.

Devine, A., Fawcett, K., Szücs, D., \& Dowker, A. (2012). Gender differences in mathematics anxiety and the relation to mathematics performance while controlling for test anxiety. Behavioral and Brain Functions, 8, 33. doi:10.1186/1744-9081-8-33

Dew, K. M. H., Galassi, J. P., \& Galassi, M. D. (1983). Mathematics anxiety: Some basic issues. Journal of Counseling Psychology, 30, 443-446.

Dreger, R. M., \& Aiken, L. R. (1957). The identification of number anxiety in a college population. Journal of Educational Psychology, 48, 344-351.

Eccles, J. S., Jacobs, J. E., \& Harold, R. D. (1990). Gender role stereotypes, expectancy effects and parents' socialization of gender differences. Journal of Social Issues, 46, 183-201.

Eden, C., Heine, A., \& Jacobs, A. M. (2013). Mathematics anxiety and its development in the course of formal schooling-A review. Psychology, 4, 27-35. doi:10.4236/psych.2013.46A2005

Etkin, A., \& Wager, T. (2007). Functional neuroimaging of anxiety: A meta-analysis of emotional processing in PTSD, social anxiety disorder and specific phobia. American Journal of Psychiatry, 164, $1476-1488$.

Eysenck, M. W. (1992). Anxiety: The cognitvie perspective. Hove, UK: Erlbaum.

Eysenck, M. W., \& Byrne, A. (1992). Anxiety and susceptibility to distraction. Personality and Individual Differences, 13, 793-798.

Eysenck, M. W., \& Calvo, M. G. (1992). Anxiety and performance: The processing efficiency theory. Cognition and Emotion, 6, 409-434.

Eysenck, M. W., Derakshan, N., Santos, R., \& Calvo, M. G. (2007). Anxiety and cognitive performance: Attentional control theory. Emotion, 7, 336-353. doi:10.1037/1528-3542.7.2.336

Fales, C. L., Barch, D. M., Burgess, G. C., Schaefer, A., Mennin, D. S., Gray, J. R., \& Braver, T. S. (2008). Anxiety and cognitive efficiency: Differential modulation of transient and sustained neural activity during a working memory task. Cognitive, Affective, \& Behavioral Neuroscience, 8, 239-253. doi:10.3758/CABN.8.3.239

Faust, M. W. (1992). Analysis of physiological reactivity in mathematics anxiety (Unpublished doctoral dissertation, Bowling Green State University, Bowling Green, Ohio).
Faust, M. W., Ashcraft, M. H., \& Fleck, D. E. (1996). Mathematics anxiety effects in simple and complex addition. Mathematical Cognition, 2, 25-62.

Fennema, E., \& Sherman, J. (1976). Fennema-Sherman Mathematcs Attitudes Scales. JSAS Catalog of Selected Documents in Psychology, 6(1), 31.

Ferguson, A. M., Maloney, E. A., Fugelsang, J., \& Risko, E. F. (2015). On the relation between math and spatial ability: The case of math anxiety. Learning and Individual Differences, 39, 1-12. doi:10. 1016/j.lindif.2015.02.007

Gehring, W. J., Himle, J., \& Nisenson, L. G. (2000). Action-monitoring dysfunction in obsessive-compulsive disorder. Psychological Science, 11, 1-6.

Geist, E. (2010). The anti-anxiety curriculum: Combating math anxiety in the classroom. Journal of Instructional Psychology, 37, 24-31.

Goetz, T., Bieg, M., Lüdtke, O., Pekrun, R., \& Hall, N. C. (2013). Do girls really experience more anxiety in mathematics? Psychological Science, 24, 2079-2087. doi:10.1177/0956797613486989

Gough, D. C. (1954). Mathemaphobia: Causes and treatments. Clearing House, 28, 290-294.

Hallion, L. S., \& Ruscio, A. M. (2011). A meta-analysis of the effect of cognitive bias modification on anxiety and depression. Psychological Bulletin, 137, 940-958. doi:10.1037/ a 0024355

Hembree, R. (1990). The nature, effects, and relief of mathematics anxiety. Journal for Research in Mathematics Education, 21, 33-46.

Holloway, I. D., \& Ansari, D. (2009). Mapping numerical magnitudes onto symbols. Journal of Experimental Child Psychology, 103, 17-29.

Hopko, D. R., Ashcraft, M. H., Gute, J., Ruggiero, K. J., \& Lewis, C. (1998). Mathematics anxiety and working memory: Support for the existence. Journal of Anxiety Disorders, 12, 343-355.

Hopko, D. R., Mahadevan, R., Bare, R. L., \& Hunt, M. A. (2003). The Abbreviated Math Anxiety Scale (AMAS): Construction, validity, and reliability. Assessment, 10, 178-182.

Hopko, D. R., McNeil, D. W., Gleason, P. J., \& Rabalais, A. E. (2002). The emotional Stroop paradigm: Performance as a function of stimulus properties and self-reported mathematics anxiety. Cognitive Therapy and Research, 26, 157-166.

Hunsley, J. (1978). Cognitive processes in mathematics anxiety and test anxiety: The role of appraisals, internal dialogue and attributions. Journal of Educational Psychology, 79, 388-392.

Isnard, J., Magnin, M., Jung, J., Mauguière, F., \& Garcia-Larrea, L. (2011). Does the insula tell our brain that we are in pain? Pain, 152, 946-951. doi:10.1016/j.pain.2010.12.025

Jamieson, J. P., Mendes, W. B., Blackstock, E., \& Schmader, T. (2010). Turning the knots in your stomach into bows: reappraising arousal improves perfromance on the GRE. Journal of Experimental Social Psychology, 46, 208-212.

Jeines, W. H. (2003). A meta-analysis: The effects of parental involvement on minority children's academic achievement. Education and Urban Society, 35, 202-218.

Kalisch, R., Wiech, K., Herrmann, K., \& Dolan, R. J. (2006). Neural correlates of self-distraction from anxiety and a process model of cognitive emotion regulation. Journal of Cognitive Neuroscience, 18, 1266-1276.

Koster, E. H. W., Crombez, G., Verschuere, B., \& De Houwer, J. (2004). Selective attention to threat in the dot probe paradigm: Differentiating vigilance and difficulty to disengage. Behaviour Research and Therapy, 42, 1183-92. doi:10. 1016/j.brat.2003.08.001

Krinzinger, H., Kaufmann, L., \& Willmes, L. (2009). Math anxiety and math ability in early primary school years. Journal of Psychoeducational Assessment, 27, 206-224.

Larson, M. J., Kaufman, D. A. S., \& Perlstein, W. M. (2009). Neural time course of conflict adaptation effects on the Stroop task. 
Neuropsychologia, 47, 663-670. doi:10.1016/j.neuropsychologia. 2008.11.013

Lazarus, M. (1974). Mathophobia: Some personal speculations. National Elementary Principal, 53, 16-22.

LeDoux, J. E. (2000). Emotional circuits in the brain. Annual Review of Neuroscience, 23, 155-184. doi:10.1146/annurev.neuro.23.1.155

LeFevre, J., Kulak, A., \& Heymans, S. (1992). Factors influencing the selection of university majors varying in mathematical content. Canadian Journal of Behavioural Science, 24, 276-289.

Lyons, I. M., \& Beilock, S. L. (2012a). Mathematics anxiety: Separating the math from the anxiety. Cerebral Cortex, 22, 2102-2110. doi:10. 1093/cercor/bhr289

Lyons, I. M., \& Beilock, S. L. (2012b). When math hurts: Math anxiety predicts pain network activation in anticipation of doing math. PLoS ONE, 7, e48076. doi:10.1371/journal.pone.0048076

Ma, X. (1999). A meta-analysis of the relationship between anxiety toward mathematics and achievement in mathematics. Journal for Research in Mathematics Education, 30, 520-540. doi:10.2307/ 749772

Ma, X., \& Xu, J. (2004). The causal ordering of mathematics anxiety and mathematics achievement: a longitudinal panel analysis. Journal of Adolescence, 27, 165-179.

MacLeod, C. M. (1991). Half a century of research on the Stroop effect: An integrative review. Psychological Bulletin, 109, 163-203. doi: 10.1037/0033-2909.109.2.163

MacLeod, C., Mathews, A., \& Tata, P. (1986). Attentional bias in emotional disorders. Journal of Abnormal Psychology, 95, 15-20. doi: 10.1037/0021-843X.95.1.15

MacLeod, C., Rutherford, E., Campbell, L., Ebsworthy, G., \& Holker, L. (2002). Selective attention and emotional vulnerability: Assessing the causal basis of their association through the experimental manipulation of attentional bias. Journal of Abnormal Psychology, 111, 107-123. doi:10.1037/0021-843X.111.1.107

Maloney, E. A., Ansari, D., \& Fugelsang, J. A. (2011). The effect of mathematics anxiety on the processing of numerical magnitude. Quarterly Journal of Experimental Psychology, 64, 10-16. doi:10. 1080/17470218.2010.533278

Maloney, E. A., Risko, E. F., Ansari, D., \& Fugelsang, J. (2010). Mathematics anxiety affects counting but not subitizing during visual enumeration. Cognition, 114, 293-297. doi:10.1016/j. cognition.2009.09.013

Maloney, E. A., Waechter, S., Risko, E. F., \& Fugelsang, J. A. (2012). Reducing the sex difference in math anxiety: The role of spatial processing ability. Learning and Individual Differences, 22, 380384. doi:10.1016/j.lindif.2012.01.001

Mathews, A., \& MacLeod, C. (2002). Induced processing biases have causal effects on anxiety. Cognition and Emotion, 16, 331-354.

Mattarella-Micke, A., Mateo, J., Kozak, M. N., Foster, K., \& Beilock, S. L. (2011). Choke or thrive? The relation between salivary cortisol and math performance depends on individual differences in working memory and math-anxiety. Emotion, 11, 1000-1005. doi:10.1037/ a0023224

McLaughlin, M. S. (1996). Comparison of a self-report questionnaire and a Stroop color-naming task (Unpublished senior thesis. Oklahoma State University, Oklahoma City, Oklahoma).

McLeod, B. D., Wood, J. J., \& Weisz, J. R. (2007). Examining the association between parenting and childhood anxiety: A meta-analysis. Clinical Psychology Review, 27, 155-172. doi:10.1016/j.cpr.2006. 09.002

McMullan, M., Jones, R., \& Lea, S. (2012). Math anxiety, self-efficacy, and ability in British undergraduate nursing students. Research in Nursing and Health, 35, 178-186.

Meece, J. L., Wigfield, A., \& Eccles, J. S. (1990). Predictors of math anxiety and its consequences for young adolescents' course enrollment intentions and performances in mathematics. Journal of Educational Psychology, 82, 60-70.

Miyake, A., Friedman, N. P., Emerson, M. J., Witzki, A. H., Howerter, A., \& Wager, T. D. (2000). The unity and diversity of executive functions and their contributions to complex "frontal lobe" tasks: A latent variable analysis. Cognitive Psychology, 41, 49-100. doi:10. 1006/cogp.1999.0734

Núñez-Peña, M. I., Guilera, G., \& Suárez-Pellicioni, M. (2013a). The Single-Item Math Anxiety Scale: An alternative way of measuring mathematical anxiety. Journal of Psychoeducational Assessment, 32, 306-317. doi:10.1177/0734282913508528

Núñez-Peña, M. I., \& Suárez-Pellicioni, M. (2014). Less precise representation of numerical magnitude in high math-anxious individuals: An ERP study of the size and distance effects. Biological Psychology, 103, 176-183.

Núñez-Peña, M. I., Suárez-Pellicioni, M., Guilera, G., \& MercadéCarranza, C. (2013b). A Spanish version of the short Mathematics Anxiety Rating Scale (sMARS). Learning and Individual Differences, 24, 204-210.

Öhman, A., Flykt, A., \& Esteves, F. (2001). Emotion drives attention: Detecting the snake in the grass. Journal of Experimental Psychology: General, 131, 466-478. doi:10.1037/0096-3445.130. 3.466

OECD. (2013). PISA 2012 assessment and analytical framework: Mathematics, reading, science, problem solving and financial literacy. Paris: OECD Publishing.

Osinsky, R., Gebhardt, H., Alexander, N., \& Hennig, J. (2012). Trait anxiety and the dynamics of attentional control. Biological Psychology, 89, 252-259. doi:10.1016/j.biopsycho.2011.10.016

Park, D., Ramirez, G., \& Beilock, S. (2014). The role of expressive writing in math anxiety. Journal of Experimental Psychology: Applied, 20, 103-111.

Paulus, M. P., \& Stein, M. B. (2006). An insular view of anxiety. Biological Psychiatry, 60, 383-387. doi:10.1016/j.biopsych.2006. 03.042

Phan, K. L., Wager, T., Taylor, S. F., \& Liberson, I. (2002). Functional neuroanatomy of emotion: a meta-analysis of emotion activation studies in PET and fMRI. NeuroImage, 16, 331-348.

Phillips, M. L., Williams, L. M., Heining, M., Herba, C. M., Russell, T., Andrew, C., . . Gray, J. A. (2004). Differential neural responses to overt and covert presentations of facial expressions of fear and disgust. NeuroImage, 21, 1484-1496. doi:10.1016/j.neuroimage.2003. 12.013

Plake, B. S., \& Parker, C. S. (1982). The development and validation of a revised version of the Mathematics Anxiety Rating Scale. Educational and Psychological Measurements, 42, 551-557.

Ramirez, G., Gunderson, E. A., Levine, S. C., \& Beilock, S. L. (2013). Math anxiety, working memory and math achievement in early elementary school. Journal of Cognition and Development, 14, 187-202.

Rauch, S. L., Savage, C. R., Alpert, N. M., Fischman, A. J., \& Jenike, M. A. (1997). The functional neuroanatomy of anxiety: A study of three disorders using positron emission tomography and symptom provocation. Biological Psychiatry, 42, 446-452.

Rauch, S. L., Shin, L. M., \& Wright, C. I. (2003). Neuroimaging studies of amygdala function in anxiety disorders. Annals of the New York Academy of Sciences, 985, 389-410.

Rauch, S. L., Whalen, P. J., Shin, L. M., McInerney, S. C., Macklin, M. L., Lasko, N. B., . . Pitman, R. K. (2000). Exaggerated amygdala response to masked facial stimuli in posttraumatic stress disorder: A functional MRI study. Biological Psychiatry, 47, 769-776.

Richardson, F. C., \& Suinn, R. M. (1972). The mathematics anxiety rating scale: Psychometric data. Journal of Counceling Psychology, 19, $551-554$

Rowe, J. B., Toni, I., Josephs, O., Frackowiak, R. S. J., \& Passingham, R. E. (2000). The prefrontal cortex: Response selection or maintenance 
within working memory? Science, 288, 1656-1660. doi:10.1126/ science.288.5471.1656

Sandman, R. S. (1980). The mathematics attitude inventory: Instrument and user's manual. Journal for Research in Mathematics Education, $11,148-149$.

Sarkar, A., Dowker, A., \& Cohen Kadosh, R. (2014). Cognitive enhancement or cognitive cost: Trait-specific outcomes of brain stimulation in the case of mathematics anxiety. Journal of Neuroscience, 34, 16605-16610. doi:10.1523/JNEUROSCI.3129-14.2014

Schachter, S., \& Singer, J. (1962). Cognitive, social, and physiological determinants of emotional state. Psychological Review, 69, 379-399.

Schmidt, N. B., Richey, J. A., Buckner, J. D., \& Timpano, K. R. (2009). Attention trainig for generalized social anxiety disorder. Journal of Abnormal Psychology, 118, 5-14. doi:10.1037/a0013643

Spielberger, C. D. (1977). The Test Anxiety Inventory. Palo Alto, CA: Consulting Psychologists Press.

Stein, M. B., Simmons, A. N., Feinstein, J. S., \& Paulus, M. P. (2007). Increased amygdala and insula activation during emotion processing in anxiety-prone subjects. American Journal of Psychiatry, 164, 318-327. doi:10.1176/appi.ajp.164.2.318

Stricker, L., \& Ward, W. (2004). Stereotype threat, inquiring about test takers' ethnicity and gender, and standardized test performance. Journal of Applied Social Psychology, 344, 665-693.

Stroop, J. R. (1935). Studies of interference in serial verbal reactions. Journal of Experimental Psychology, 18, 643-662. doi:10.1037/ 0096-3445.121.1.15

Suárez-Pellicioni, M., Núñez-Peña, M. I., \& Colomé, A. (2013a). Abnormal error monitoring in math-anxious individuals: Evidence from error-related brain potentials. PLOS ONE, 8, e81143. doi:10. 1371/journal.pone.0081143

Suárez-Pellicioni, M., Núñez-Peña, M. I., \& Colomé, A. (2013b). Mathematical anxiety effects on simple arithmetic processing efficiency: An event-related potential study. Biological Psychology, 94, 517-526.

Suárez-Pellicioni, M., Nuñez-Peña, M. I., \& Colomé, A. (2014). Reactive recruitment of attentional control in math anxiety: An ERP study of numeric conflict monitoring and adaptation. PLoS ONE, 9, e99579. doi:10.1371/journal.pone.0099579

Suinn, R. M., Edie, C. A., \& Spinelli, P. R. (1970). Accelerated massed desensitization: Innovation in short-term treatment. Behavior Therapy, 1, 303-311.

Suri, R., Monroe, K. B., \& Koe, U. (2013). Math anxiety and its effects on consumers' preference for price promotion formats. Journal of the Academy of Marketing Science, 41, 271-282.

Swars, S. L., Daane, C. J., \& Giesen, J. (2006). Mathematics anxiety and mathematics teacher efficacy: What is the relationship in elementary preservice teachers? School Science and Mathematics, 106, 306-315.

Taylor, J. (1953). A personality scale of manifest anxiety. Journal of Abnormal and Social Psychology, 48, 285-290.

Thomas, G., \& Dowker, A. (2000, September). Mathematics anxiety and related factors in young children. Paper presented at the British
Psychological Society Developmental Section Conference, Bristol, UK.

Tobias, S. (1978). Overcoming math anxiety. Boston, MA: Houghton Mifflin.

Tuholski, S. W., Engle, R. W., \& Baylis, G. C. (2001). Individual differences in working memory capacity and enumeration. Memory \& Cognition, 29, 484-492. doi:10.3758/BF03196399

Turner, J. C., Midgley, C., Meyer, D. K., Gheen, M., Anderman, E. M., Kang, Y., \& Patrick, H. (2002). The classroom environment and students' reports of avoidance strategies in mathematics: A multimethod study. Journal of Educational Psychology, 94, 88106. doi:10.1037/0022-0663.94.1.88

Van Opstal, F., Gevers, W., De Moor, W., \& Verguts, T. (2008). Dissecting the symbolic distance effect: Comparison and priming effects in numerical and nonnumerical orders. Psychonomic Bulletin \& Review, 15, 419-425. doi:10.3758/PBR.15.2.419

Vanderhasselt, M.-A., De Raedt, R., \& Baeken, C. (2009). Dorsolateral prefrontal cortex and Stroop performance: Tackling the lateralization. Psychonomic Bulletin \& Review, 16, 609-612. doi:10.3758/ PBR. 16.3.609

Verguts, T., Fias, W., \& Stevens, M. (2005). A model of exact smallnumber representation. Psychonomic Bulletin \& Review, 12, 6680. doi:10.3758/BF03196349

Vukovic, R. K., Roberts, S. O., \& Wright, L. G. (2013). From parental involvement to children's mathematical performance: The role of mathematics anxiety. Early Education and Development, 24, 446-467.

Wang, Z., Hart, S. A., Kovas, Y., Lukowski, S., Soden, B., Thompson, L. A., ... Petrill, S. A. (2014). Who is afraid of math? Two sources of genetic variance for mathematical anxiety. Journal of Child Psychology and Psychiatry, 55, 1056-1064. doi:10.1111/ jcpp. 12224

Weinberg, A., Olvet, D. M., \& Hajcak, G. (2010). Increased error-related brain activity in generalized anxiety disorder. Biological Psychology, 85, 472-480.

West, R. (2003). Neural correlates of cognitive control and conflict detection in the Stroop and digitlocation tasks. Neuropsychologia, $41,1122-1135$.

Williams, J. M., Mathews, A., \& MacLeod, C. (1996). The emotional Stroop task and psychopathology. Psychological Bulletin, 120, 3-24.

Wright, C. I., Martis, B., McMullin, K., Shin, L. M., \& Rauch, S. L. (2003). Amygdala and insular responses to emotionally valenced human faces in small animal specific phobia. Biological Psychiatry, 54, 1067-1076.

Wu, S. S., Barth, M., Amin, H., Malcarne, V., \& Menon, V. (2012). Math anxiety in second and third graders and its relation to mathematics achievement. Frontiers in Psychology, 3(162), 1-11. doi:10.3389/ fpsyg.2012.00162

Young, C. B., Wu, S. S., \& Menon, V. (2012). The neurodevelopmental basis of math anxiety. Psychological Science, 23, 492-501. doi:10. 1177/0956797611429134 